\title{
Computer Aided Instruction: A Study Of Student Evaluations And Academic Performance
}

\author{
David Collins, Bellarmine University, USA \\ Alan Deck, Bellarmine University, USA \\ Myra McCrickard, Bellarmine University, USA
}

\begin{abstract}
Computer aided instruction (CAI) encompasses a broad range of computer technologies that supplement the classroom learning environment and can dramatically increase a student's access to information. Criticism of CAI generally focuses on two issues: it lacks an adequate foundation in educational theory and the software is difficult to implement and use. This paper describes the educational use of CAI in two different courses at a small, private university and the implementation and use experiences of the instructors. One instructor used Homework Manager in Principles of Financial Accounting and the other instructor used Aplia in Principles of Microeconomics. It is shown that the use of CAI is pedagogically effective and that currently available applications are easy to integrate into the student's in-class experience. The paper also reports on the impact that using CAI has on student evaluations of both the course and the instructor and on student grades. For student evaluations, mean responses were compared on ten questions believed to be influenced by the switch from traditional homework assignments to CAIbased homework assignments. While differences were generally in the expected direction, it could not be shown that CAI had a direct impact on student evaluations of either the course or the instructor. For student grades, final exam grades were compared before and after the adoption of CAI. It is shown that the use of CAI significantly increased student final exam grades.
\end{abstract}

Keywords: pedagogy, student performance, computer based instruction, course evaluations

\section{INTRODUCTION}

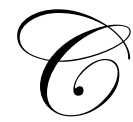

omputer aided instruction (CAI) encompasses a broad range of computer technologies that supplement the classroom learning environment and can dramatically increase a student's access to information. CAI programs, which can include directed drills, practice exercises, and communication between students and teachers, can adapt to the abilities and preferences of individual students and increase the amount of personalized instruction a student receives. Students also benefit from the immediate feedback provided by computers and most of them appreciate the self-paced learning environment. At its best, CAI engages student interest, motivates them to learn, and increases their personal responsibility for learning.

Criticism of CAI generally focuses on two issues. First, it is argued that much of the available software lacks an adequate foundation in educational theory. Second, it is argued that the software is difficult to implement and use. Most CAI studies focus either on educational effectiveness for a particular subject or the student's experience in using the software. Extant studies do not show a clear pattern of support for either of those issues.

This paper reports on two separate uses of CAI at a small, private university: in a principles of financial accounting course and in a principles of microeconomics course. Although both instructors used CAI to supplement the student's in-class experiences, each used different computer programs and different methodologies. This paper describes the educational use of CAI in these two different courses and the implementation and use results 
experienced by the instructors. Also, in addition to educational effectiveness and the student's experience, this study reports on the impact that using CAI has on student evaluations of both the course and the instructor.

\section{COMPUTER AIDED INSTRUCTION}

Computer aided instruction has a rich history and developed concurrently with the development of electronic computers (Daniel, 1999). CAI began in the mid-1950s as a collaboration between Stanford University and IBM but grew slowly until the arrival of personal computers in the 1980s. Today there are few schools in the United States that do not have computers available for student use, and don't use some form of CAI on those computers.

While educational effectiveness and implementation issues have been common, CAI has remained popular among educators who maintain a belief that it is a useful supplement to classroom activities. A number of studies have reported that it can be successful in raising exam scores, improving student attitudes, and reducing the time needed to master course materials (Canham and Dickie, 1986; Collis, Obserg, and Sherra, 1988-89; Nipp and Straub, 1986). It also has been shown that students like the mode of presentation (Anderson-Harper, Mason, and Popovich, 1988; Brown, 1995), that it is viewed as a positive experience (Deardoff, 1986), and that it is suitable for individual learning needs (Dobson, 1995).

However, Kulik and Kulik (1989) concluded that more well-designed research is needed before any real conclusions about the effectiveness of CAI can be drawn. Bork (1991) suggests that much of what is available is of little use. Cherry (1991) found that there was no significant difference between CAI and lectures as an effective teaching technique and Garrett (1995) reported mixed results when comparing CAI and lectures. Thus, while educational effectiveness may exist for specific applications, it is difficult to conclude that such effectiveness is common across a large range of disciplines.

Criticism about software design and implementation is well expressed by Walbert (1989), who stated that the majority of CAI applications are naïve and mundane. Blecha (1991) list common design problems with CAI software: tedious keystrokes, unnecessarily repetitive operations, software that is difficult to use, and minimal pedagogical value of programs that hide the inner workings of models. Harrington (1989) concludes that CAI programs lack any advantages over printed materials and do not take advantage of the feedback potential of computers.

To address many of the shortcomings - perceived and real - of CAI, Walbert (1989) offers specific suggestions for enhancing CAI:

1) Include menu-driven open-model simulations, database spreadsheets, and an electronic sketchpad.

2) Engage the student in Socratic dialogues with interactive questions and answers leading to the learning objective.

3) Allow freedom of navigation so that the student can return to previous explanations or skip a particular troublesome problem.

4) Provide an electronic sketchpad using the mouse to point to, draw, and modify graphs in response to questions.

5) Give immediate feedback to correct and incorrect answers.

6) Include a help facility to answer student questions or provide a reference to the text.

7) Allow students to change the parameters in the spreadsheets.

8) Vary level of difficulty of problems so that some require only recollection of facts and arguments from the text, others require the student to analyze a problem, and still others require the student to synthesize the techniques.

9) Include high-quality graphics, animation, and sound.

10) Provide spreadsheets with graphical capabilities.

11) Write software for a specific textbook and do not try to replace the text.

12) Provide a manual or on-line help. 
Daniel (1999) provides a similar, but somewhat different set of criteria for CAI:

1) The software should be as easy to use as a blackboard or notebook but provide additional capability including mathematical accuracy, animations, manipulation, and rapid calculation.

2) The software should span the learning stages from initial exposure to an idea to idea to understanding and application. Theoretical modeling, empirical estimation, and policy experimentation should be integrated to minimize student effort required to apply the theory.

3) The software should present a multiplicity of integrated approaches: verbal explanations, textual presentation, mathematical equations, graphical modeling, animations, and exercises. It should be able to accommodate different learning styles.

4) The instructional tools should be flexible and adaptable enough to extend to new problems and topics in economics as they arise.

5) The courseware should be adaptable to different levels of instruction: principles, intermediate, and advanced.

6) The courseware should not merely supplement a textbook but should be part of an integrated courseware system including presentation materials, textbook, study guide, workbook, and testing materials that make use of the same set of interactive computer tools.

Currently available CAI programs appear to address many of the past criticisms and appear to incorporate many of the suggestions made by both Walbert and Daniel. The programs reported on in this study are shown to be pedagogically effective within the two separate disciplines and have been successfully implemented and integrated into the student's in-class experience.

\section{IMPLEMENTING CAI IN PRINCIPLES OF MICROECONOMICS AND PRINCIPLES OF FINANCIAL ACCOUNTING}

As is the case with quantitative courses, practice and repetition are considered key factors for student success in both economics and accounting courses. The focus of both courses is on the development of tools and methodologies, which students are expected to use in solving a variety of problems. Many students find this very challenging because the ability to apply methodologies requires a deeper level of understanding than simply the ability to repeat lecture and text material. This often requires different study habits than those students may have previously used. To maximize their learning, students are encouraged to read text material before coming to class and to actively work on the concepts and principles covered in class by completing problems and testing themselves on the main topics being discussed in class.

The need for students to be actively engaged in the learning process can create a pedagogical dilemma. Instructors recognize that completing chapter readings and homework assignments significantly increases the student's ability to retain what is being taught, recognize alternative situations to which the concepts can be applied, and see the connection between topics throughout the course. Yet many students, particularly freshman, may not understand the amount of effort required to learn the subject matter at this cognitive level and may not have the time management skills needed to achieve the disciplined study required by more rigorous courses. To address this dilemma and to insure that students are actively engaged in the learning process, instructors have typically given written homework assignments and/or frequent quizzes. Such methods are not necessarily optimal, for either instructors or students, because developing, distributing, and grading assignments and quizzes is often very time intensive, particularly for large classes. This implies an information lag between the learning process and an instructor's knowledge of what students are learning.

One option for motivating students and reducing this information lag is to incorporate computer aided instruction as a pedagogical tool. For the instructor, an appropriate CAI tool can reduce the time needed to develop, distribute, and grade assignments and quizzes; with the added benefit of providing more immediate feedback - to both instructors and students - of the learning process. This can enable the instructor to reinforce those topics not well understood by students before moving on to the next learning objective. For students, the active learning (and 
immediate feedback) promoted by CAI should lead to higher grades and, with more positive experiences in the course, higher student evaluations.

\section{CAI IN PRINCIPLES OF MICROECONOMICS USING APLIA}

Aplia is an online course and homework management system developed by Stanford economist Paul Romer in 2001 and first available for use in 2002. Because of its recent development, Aplia benefited from prior research and many of the suggestions to improve CAI have been incorporated into Aplia. The core elements of Aplia include: (1) Interactive content - problem sets, experiments, news analyses, and tutorials (2) Digital edition of the textbook (3) Easy-to-use course management system (4) Personalized customer support and (5) Instant reports and grade book. While Aplia has generalized course materials that can be used in many courses, the company also has developed materials for specific textbooks. For example, Aplia materials have been developed that are specific to 34 principles of economics textbooks.

Romer's objective in creating Aplia was to engage students more fully in their own learning by increasing regular effort and preparation outside the classroom. This goal was driven by his belief that student effort is the most important factor in academic success. Aplia includes two options for ensuring student engagement: Grade It Now and parallel practice/graded problem sets. Grade It Now allows students to attempt a question three times (failed attempts are followed up with similar questions). Immediate feedback is given after each attempt and the final score is determined by an average of attempted questions. Parallel practice/graded problem sets allow students to practice problems in an ungraded format followed by a problem set that is graded. Immediate feedback is provided to students in practice mode, while feedback is given on graded problem sets when the assignment is due. The instructor also can alter problem sets by adding or deleting questions.

Aplia contains interactive tutorials with questions that vary in level of difficulty and that often are composed of a series of questions that increase the student's ability to answer a complex question by tackling it in small steps. Students who have had previous exposure to economics, or who pick up the concepts quickly, may skip the tutorials and/or the practice problem sets and move directly to the graded problem sets. Alternatively, students requiring more work may complete the tutorials in addition to the practice and graded problem sets. This feature of Aplia is especially helpful when an instructor wants to ensure that students have an adequate mathematics preparation as the course begins. Two math tests and a tutorial are included and the lowest math score is dropped. Students that earn a good score on the first math test do not have to do additional work, while students who need the review complete the tutorial then take the second math test. Another useful feature of Aplia is the news analyses, which incorporate current events into the problem sets to show the relationship between theory and application more clearly.

Beginning in the fall of 2006 a principles of microeconomic course adopted an integrated textbook version of Aplia, which provided students with an online version of their text and assignments specific to the text. During the course, students were assigned parallel practice/graded problem sets and news analyses for each chapter (Grade It Now was available beginning in fall 2008). Because students should be familiar with terminology and basic concepts, they were required to read the chapter and to complete the practice problem set before the class lecture/discussion on that material. During the class discussion of each chapter, students completed the news analyses on current topics, and at the end of the chapter they completed the graded problem set. Throughout this process, students could refer to the initial problem set with detailed answers to all questions.

Aplia facilitated learning because students came to class better prepared and class participation increased because students had thought about the material prior to class. Because students were familiar with basic terminology and concepts, class time could include less lecture and more active learning activities without worrying about whether the basic material was covered. As scores on both practice and graded assignments were obtained, class time could be devoted to topics that students found difficult and students could use Aplia to review those concepts before attempting a new topic. Also, Aplia's announcement feature was used to encourage students in their progress or talk about course topics when the Aplia results indicated that more work was needed. 
Aplia's ease of use and immediate feedback allows the instructor to assign more questions and, so, to cover more topics in greater depth. Since it replaced the homework assignments and weekly quizzes given in the past, the time formally committed to those activities provided more time to help students and to plan class activities. When students came in for help, their student report provided a quick picture of the general understanding of course topics as well as the specific areas and questions that were troublesome. The reports also highlighted those students not doing the requisite work in Aplia, which enabled early intervention and showed the student that the instructor was paying attention to and concerned with their performance in the course.

\section{CAI IN PRINCIPLES OF FINANCIAL ACCOUNTING USING HOMEWORK MANAGER}

Homework Manager was implemented in the Fall of 2007 in a principles of financial accounting course. Homework Manager was chosen because it was the companion CAI for the text being using in the course. Whereas Aplia was integrated with the economics text, Homework Manager gave students the option of an integrated text CAI or purchasing the text and CAI separately. The first option provided students with a less expensive means of acquiring the necessary course materials, but the second provided students with a hard-copy version of the text for studying.

As with Aplia, Homework Manager includes many alternative uses (including quizzes and exams); however, its use in the accounting course was limited to homework assignments. In using Homework Manager for homework, the instructor has many options and can tailor the homework assignments based on what is believed to provide the best help for students. These options include, but are not limited to:

a. Allowing students to attempt the homework either once or multiple times before the due date.

b. Providing feedback on the assignments as students answer each question, after completion of each repetition of the entire assignment, or after the assignment is due and cannot be changed.

c. $\quad$ Allowing time limits or unlimited time for each assignment.

d. Being able to assign homework exactly as it appears in the text or to assign homework that was essentially the same as in the text, but with numbers changed each time the student returned to that question.

In the course where Homework Manager was implemented, the instructor used a mixture of questions that were identical to those in the text and some that were not. Students are allowed access to the solution manuals for all accounting courses. Thus, students were encouraged to first attempt the assigned homework taken directly from the text and then review their errors based on the analysis provided by the solutions manual. The students were then encouraged to attempt the changed questions.

The instructor further allowed the students to attempt the homework assignment as often as they wished before a posted deadline date, with a grade and feedback given to the student after each attempt. Allowing assignments to be reworked multiple times gave students willing to expend the effort the opportunity to improve their homework grade. One limitation was that it gave students the opportunity to guess at answers that were incorrect, without actually working through the problem. However, students soon found that it took less time to study items missed before reworking than it did just to guess multiple times. In addition, since some of the questions changed each time the student returned to the assignment, simply guessing each time provided no benefits.

The feedback provided by Homework Manager is excellent. It points out incorrect answers and explains why those answers are incorrect. The basic limitation to Homework Manger is that the only types of questions that can be asked are those where the student enters either an account title or a number. While these types of questions are important to a student's understanding of the basic accounting model and help the students work problems, they do not allow a student to provide any type of in-depth analysis.

\section{DATA AND METHODOLOGY}

Data was obtained from student course evaluations, homework scores, and final exam scores for the principles of microeconomics and the principles of financial accounting courses. Aplia was implemented in the 
microeconomics course during the fall semester of 2006 while Homework Manager was implemented in the accounting course during the fall semester of 2007. To consider both pre and post CAI results, the data for the microeconomics course covers the period from fall 2005 to spring 2008, while that for the accounting course covers the period from fall 2006 to spring 2008. The total number of number of microeconomics sections in the data set was 17 ( 6 sections before CAI and 11 after CAI). The total number of number of accounting sections in the data set was 6 ( 2 sections before CAI and 4 after CAI). The sample size was 311 for the microeconomics course and 95 for the accounting course.

Final exam scores (FINAL EXAM) were used rather than final course grades because the homework score was a component of the final course grade. CAI represents the homework score achieved by the students in each of the courses. SPRING controls for possible differences in final exam scores between fall and spring semesters that might result because weaker students often are advised to take these courses in the spring semester. Because CAI was used in the microeconomics course for two years, a TIME variable was included to examine whether the use of CAI is more effective over time. If a learning curve exists as new technology is integrated into the classroom, one would expect the effectiveness of CAI to increase. The effect of CAI on final exam scores is expected to be positive and was examined by regressing the final exam scores on the homework scores (the Aplia score in the microeconomics course and the Homework Manager score in the financial accounting course), while controlling for SPRING (both courses) and TIME (the microeconomics course only).

As is typical at most universities, end of semester student evaluations are administered every semester in each section of Principles of Financial Accounting and Principles of Microeconomics. The evaluations ask students to rate their instructors and courses on a series of questions, using a five point scale. The answers ranged from Strongly Agree (5) to Strongly Disagree (1). The number of responses for each question and the mean are reported to the instructor. Weighted means of the student responses were used for this study. Because the evaluation form is used university-wide, the questions were not directly tailored to focus on the student perceptions of the advantages and disadvantages of using CAI. The questions noted below were chosen for this study because it was believed they might be influenced by the switch to CAI:

1. The contents of the assignments contribute to my understanding of the subject.

2. The instructor has adequate means for evaluating my learning.

3. The methods being used for evaluating my work are reasonable.

4. The course appears to have been carefully planned.

5. Compared with other courses on this level carrying an equal amount of credit, the effort I put into this course is as much as in other courses.

6. The instructor provides useful feedback on student progress.

7. In this course, I am learning much.

8. The out of class assignments are challenging.

9. Overall, I rate this instructor a good teacher.

10. Examinations cover material or skills emphasized in the course.

The effect of CAI on student evaluations is expected to be positive and was examined by regressing the weighted mean for each question against a dummy variable: $\mathrm{CAI}(0=$ without $\mathrm{CAI}, 1=$ with $\mathrm{CAI})$.

\section{RESULTS}

The means of the variables used in the regressions for the final exam score (FINAL EXAM) are included in Table 1. Of interest in this study, while the average FINAL EXAM scores are quite different (67.09 for microeconomics vs. 49.28 for financial accounting), the average CAI scores are almost identical (74.33 for microeconomics and 74.97 for financial accounting). This may suggest that the mechanics of using a CAI tool (how Aplia works vs. how Homework Manager works) does not significantly impact the outcomes achieved by students.

Regression results for the data on final exam scores for microeconomics and financial accounting are reported in Table 2. With the exception of SPRING, all of the variables tested are significant at the $1 \%$ level. While 
SPRING is in the expected direction for microeconomics, it is not so for financial accounting. However, since it is not significant, it does not appear that there is a difference between fall and spring semester for these courses. The intercept terms for both courses (21.901 and 25.438) are consistent with what one would expect if a student simply guessed at the multiple choice questions on the final exam.

The results for the CAI variable are, as expected, both positive and significant and indicate that the use of CAI improves final exam scores. Each one-point increase on the Aplia assignments adds 0.61 of a point on the final exam in microeconomics. For each one-point increase on Homework Manager assignments, our results indicate an increase of 0.24 of a point on the final exam in financial accounting. For the microeconomics course only, the TIME variable is both positive and significant and added 4.846 points to the final exam score in year two compared to year one. This indicates, that with instructor experience, the use of CAI may be more effective over time. However, follow-up work may be necessary to determine if this result continues past the second year of use.

As noted above, the data on student evaluations included student responses to a survey administered in class at the end of the semester. We used the average response for each question by course section to create a weighted mean in our analysis (Table 3). Regression results indicate that CAI was not significant in explaining the responses to any of the 10 student evaluation questions chosen. This suggests that the use of CAI, in and of itself, does not impact student perceptions of course quality. Alternatively, this may be due to the fact that the responses are not identified by student, so the aggregated data masks any effect of CAI on student perceptions of course quality. However, as Table 3 shows, while the response differences are not large enough to be significant, at least for the microeconomics course, they generally are positive indicating a possible improvement from the use of CAI in student perceptions of course quality. Because of the mixed results for the two courses, further study in this area is needed.

\section{CONCLUSION}

Although our regression results indicated that CAI was not significant in explaining the responses to questions on student evaluations, we did find that course sections in microeconomics and financial accounting that incorporated CAI (Aplia and Homework Manager respectively) experienced higher final exam scores. This is consistent with the literature on computer based instruction. Students who do homework regularly with quick feedback get better results on test scores. This is especially important for disciplines that are based on analytical thinking in which students, particularly weaker students, may need more practice. It also is important for first-year college students as they enter an environment with less monitoring of homework.

\section{AUTHOR INFORMATION}

Dr. David T. Collins is an Associate Professor of Accounting at Bellarmine University. He earned a B.A. in accounting and a Master of Accountancy from the University of South Florida. He completed his Ph.D. at Georgia State University in accounting and decision support systems. His research interests include financial analysis, information technology, and international accounting.

Dr. Alan B. Deck, CPA, CMA is an Associate Professor of Accounting at Bellarmine University. He earned a B.B.A. in accounting at Texas Christian University and a Ph.D. from The University of Alabama. He was formerly a staff accountant with Westinghouse and a AIS consultant for various companies in the southern Louisiana area.

Dr. Myra McCrickard is a Professor of Economics at Bellarmine University. She earned her B.S. in biology from the University of Richmond and an M.A. in economics from Appalachian State University. She completed her Ph.D. at the University of North Carolina with fields in macroeconomics and labor economics. Her research interests include labor economics, health care, and economic education. 


\section{TABLES}

Table 1: Means of Variables

Microeconomics

Financial Accounting

\begin{tabular}{|c|c|c|}
\hline FINAL EXAM & 67.09 & 49.28 \\
\hline CAI & 74.33 & 74.97 \\
\hline SPRING & 0.47 & 0.51 \\
\hline TIME & 0.94 & Not Used \\
\hline Sample Size & 311 & 95 \\
\hline
\end{tabular}

Table 2: Regression Results for Final Exam Scores in Microeconomics and Financial Accounting

\begin{tabular}{|c|c|c|}
\multicolumn{2}{c}{ Microeconomics } & Financial Accounting \\
\hline \multirow{2}{*}{ CAI } & 0.610 & 0.24 \\
& $(0.00)$ & $10.01)$ \\
\hline \multirow{2}{*}{ SPRING } & -10.010 & $(0.46$ \\
& $(0.00)$ & Not Used \\
\hline \multirow{2}{*}{ TIME } & 4.846 & 25.438 \\
& $(0.00)$ & $(0.00)$ \\
\hline \multirow{2}{*}{ INTERCEPT } & 21.901 & 0.11 \\
\hline
\end{tabular}

p-values in parentheses

Table 3: Weighted Means of Student Evaluations Pre- and Post- Use of CAI

Survey Question

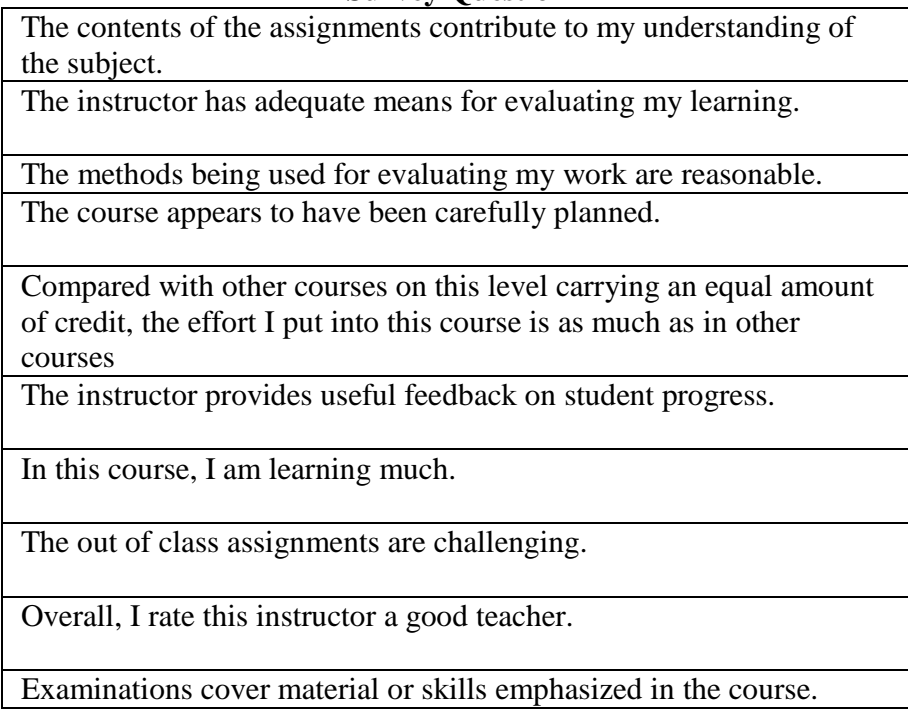

\begin{tabular}{|c|c|c|}
\hline \begin{tabular}{|l|l|} 
Pre- \\
CAI
\end{tabular} & CAI & Diff. \\
\hline 4.50 & 4.63 & 0.13 \\
\hline 4.30 & 4.55 & 0.25 \\
\hline 4.23 & 4.36 & 0.13 \\
\hline 4.58 & 4.66 & 0.07 \\
\hline 4.37 & 4.45 & 0.08 \\
\hline 4.33 & 4.42 & 0.09 \\
\hline 4.37 & 4.57 & 0.20 \\
\hline 4.52 & 4.57 & 0.05 \\
\hline 4.52 & 4.66 & 0.15 \\
\hline 4.52 & 4.62 & 0.10 \\
\hline
\end{tabular}

Financial Accounting
\begin{tabular}{|c|c|c|}
\hline $\begin{array}{r}\text { Pre- } \\
\text { CAI }\end{array}$ & CAI & Diff. \\
\hline 4.77 & 4.73 & -0.05 \\
\hline 4.65 & 4.66 & 0.01 \\
\hline 4.50 & 4.56 & 0.06 \\
\hline 4.69 & 4.54 & -0.15 \\
\hline 4.47 & 4.41 & -0.06 \\
\hline 4.19 & 4.38 & 0.20 \\
\hline 4.71 & 4.68 & -0.03 \\
\hline 4.78 & 4.70 & -0.08 \\
\hline 4.65 & 4.78 & 0.12 \\
\hline 4.53 & 4.08 & -0.45 \\
\hline
\end{tabular}




\section{BIBLIOGRAPHY}

1. Anderson-Harper, Heidi M., Holly L. Mason and Nicholas G. Popovich. Developing, Implementing and Evaluating Microcomputer Instruction in a Nonprescription Drug Course. American Journal of Pharmaceutical Education 52 (Fall 1988): 259-66.

2. Blecha, B.J. Economic Pedagogy and Microcomputer Software. Social Science Computer Review 9 (Winter 1991): 541-57.

3. Bork, Alfred. Is Technology-Based Learning Effective? Computer Education 63 (Fall 1991): 6-14.

4. Brown, Alan. Evaluation of Teaching and Learning Processes in a Computer-Supported Mechanical Engineering Course. Computers Education 25 (September 1995): 59-65.

5. Canham, Geoffrey W. Rayner and William Dickie. The Development of a Computer-Assisted Drill Program. Journal of Computers in Mathematics and Science Teaching 5 (Spring 1986): 46-47.

6. Cherry, Joan M. An Experimental Investigation of Two Types of Instruction for OPAC Users. Canadian Journal of Information Science 16 (December 1991): 2-22.

7. Collis, Betty, Antoinette Obserg and Wes Sherra. An Evaluation of Computer-Based Instruction in Statistical Techniques for Education and Social Work Students. Journal of Educational Technology Systems 17 (1988-89): 59-71.

8. Daniel, Joseph I. Computer-Aided Instruction on the World Wide Web: The Third Generation. Journal of Economic Education (Spring 1999): 163-174.

9. Deardoff, William W. Computerized Health Education: A Comparison with Traditional Format. Health Education Quarterly 13 (Spring 1986): 61-72.

10. Dobson, E.L. An Evaluation of the Student Response to Electronics Teaching Using a CAL Package. Computers Education 25 (September 1995): 13-20.

11. Garrett, Rick L. Computer-Assisted Instruction in 2-Year Colleges: Technology for Innovative Teaching. Community College Journal of Research and Practice 19 (November-December 1995): 529-36.

12. Harrington, James P. Computer-Assisted Instruction for End-Users: Our Pandora's Box. Library Software Review 8 (May/June 1989): 152-4.

13. Kulik, James A. and Chen-Lin C. Kulik. Effectiveness of Computer-Based Instruction. School Library Media Quarterly 17 (Spring 1989): 156-9.

14. Nipp, Deanna and Ron Straub. The Design and Implementation of a Microcomputer Program for Library Orientation. Research Strategies 4 (Spring 1986): 60-67.

15. Walbert, M.S. Writing Better Software for Economics Principles Textbooks. Journal of Economic Education 20 (Summer 1989): 281-89. 


\section{NOTES}

